\title{
Review of Some Methods of Determining in-Situ Saturated Hydraulic Conductivity of Soil
}

\author{
Audu Danladi ${ }^{1}$, Ibrahim Ahmed Usman ${ }^{2}$, Usman Danladi Drambi ${ }^{2,}$, , Adanu Emmanuel Otache ${ }^{3}$, \\ Yakubu Musa ${ }^{3}$ \\ ${ }^{1}$ Department of Soil Science, Federal University Kashere, Gombe, Nigeria \\ ${ }^{2}$ Department of Agricultural and Bioresource Engineering, Abubakar Tafawa Balewa University, Bauchi, Nigeria \\ ${ }^{3}$ Federal College of Education (Technical), Gombe, Nigeria
}

\section{Email address:}

danladimsh@gmail.com (A. Danladi), uiahmed@atbu.edu.ng (I. A. Usman),ddusman@atbu.edu.ng (U. D. Drambi), emmazone4@yahoo.com (A. E. Otache), longsy4908@gmail.com (Y. Musa)

${ }^{*}$ Corresponding author

\section{To cite this article:}

Audu Danladi, Ibrahim Ahmed Usman, Usman Danladi Drambi, Adanu Emmanuel Otache, Yakubu Musa. Review of Some Methods of Determining in-Situ Saturated Hydraulic Conductivity of Soil. American Journal of Science, Engineering and Technology.

Vol. 3, No. 3, 2018, pp. 53-64. doi: 10.11648/j.ajset.20180303.11

Received: August 31, 2018; Accepted: September 13, 2018; Published: November 13, 2018

\begin{abstract}
In-situ determination of $\mathrm{K}$ is important especially when the physical features of the soil system in question is to be characterized as accurately as possible. It gives more reliable values because there is minimal disturbance of the soil. It is more representative of the physical reality than the other methods. The objective of this study is therefore to review some of the in-situ methods of determining permeability, $\mathrm{K}$ of a soil, stating the conditions, advantages and disadvantages of each of the methods, thereby helping in proper selection of in-situ method to be adopted for a given soil, land terrain and type of aquifer. There are various methods of determining Saturated Hydraulic Conductivity, K of a soil. Application of each of the methods varies depending on the characteristics of the soil such as land terrain, soil water table and type of aquifer present. In this paper, nine insitu methods, which include auger hole, two types of well pumping tests, piezometer, two well, tube, four well, tracer test, point dilution and cone permeameter, as well as thirteen types and fifteen formulae were reviewed. The advantages and disadvantages as well as conditions for use of each of the nine in-situ methods were stated. Out of the nine methods studied, the non-equilibrium condition for determination of $\mathrm{R}$ for wells penetrating a confined aquifer is found to be the most reliable. It is obvious that cone permeameter is the fastest and simplest of measuring $\mathrm{K}$ at different depths in a single push without the removal of soil or water from the hole, $\mathrm{K}$ is automatically measured within 10 minutes as the device's probe is pushed into the desired depth in the ground. In terms of reliability, well pumping test of the non-equilibrium type is the most reliable and produces accurate results. Every other method is more or less related to each other and gives acceptable values of $\mathrm{K}$.
\end{abstract}

Keywords: Hydraulic Conductivity, Confined Aquifer, Unconfined Aquifer, Water Table, Piezometer, Permeameter

\section{Introduction}

Saturated hydraulic conductivity, $\mathrm{K}$, of a soil is a measure of the soil's ability to transmit water under a hydraulic gradient, i. It is defined by the Darcy's law as:

$$
\mathrm{K}=\frac{\mathrm{V}}{\mathrm{i}}=\mathrm{V} /\left(\frac{\mathrm{dh}}{\mathrm{dz}}\right)
$$

Where $\mathrm{V}$ is Darcy's velocity, $\mathrm{h}$ is the hydraulic head and $\mathrm{z}$ is the vertical distance. The term coefficient of permeability is also sometimes used as a synonym for $\mathrm{K}$. On the basis of Equation (1), $\mathrm{K}$ is defined as the ratio of Darcy's velocity to the applied hydraulic gradient with the dimensions of length per unit time $\left(\mathrm{LT}^{-1}\right) . \mathrm{K}$ depends on the soil grain size, the structure of the soil matrix, its stability and the type of soil fluid in the soil matrix. The important properties relevant to the solid matrix of the soil include pore-size distribution, pore shape, tortuosity, specific surface and porosity. In relation to the soil fluid, the important properties include fluid density and fluid viscosity $([1,2])$.

$\mathrm{K}$ can also be expressed as: 


$$
\mathrm{K}=\mathrm{k} \rho \mathrm{g} / \mu
$$

Where $\mathrm{k}$, called the intrinsic permeability of the soil, depends only on properties of the solid matrix and $\rho g / \mu$, called the fluidity of the liquid, represents the properties of the percolating fluid. The $\mathrm{k}$ has the dimensions of area $\left(\mathrm{L}^{2}\right)$ and $\rho g / \mu$ the dimensions of $\left(\mathrm{L}^{-1} \mathrm{~T}^{-1}\right)$.

In-situ determination of $\mathrm{K}$ is important especially when the physical features of the soil system in question is to be characterized as accurately as possible. It gives more reliable values because there is minimal disturbance of the soil. It is more representative of the physical reality than the other methods [3]. In general, in-situ methods (unlike other methods) take into account the influences of both the vertical and horizontal directions and represent an average value of $\mathrm{K}$. In-situ method is very important especially in highly stratified soils where the value of $\mathrm{K}$ measured would reflect the domination of the most permeable layer in the soil profile. Furthermore, by appropriately selecting the specific method to be used in the field, the in-situ values of the vertical and horizontal components of $\mathrm{K}$ could be determined independently in each layer of stratified soil [4].

The objective of this study is therefore to review some of the in-situ methods of determining permeability, $\mathrm{K}$ of a soil, stating the conditions, advantages and disadvantages of each of the methods, thereby helping in proper selection of in-situ method to be adopted for a given soil, land terrain and type of aquifer. Obtaining accurate value of $\mathrm{K}$ is very important in irrigation, modelling ground water flow, solute transport, and flow through earth dams, drainage design and seepage under sheet pile works $([5,6])$.

\section{Methods of Determining in-Situ $K$ of a Soil}

\subsection{The Auger-Hole Method}

The auger-hole method is a reliable method for measuring $\mathrm{K}$ of soil below a water table. It is mostly used in the design of drainage systems in waterlogged land and in seepage investigations [7]. The method was originally carried out by [8] and was improved [9].

The auger-hole method consists of preparing a cavity in the ground partially penetrating an aquifer with minimal disturbance of the soil. In the cavity, the water level in the hole is allowed to coincide with that of the water table. The water in the hole is removed completely and the rate of the rise of the water level within the cavity is measured [10]. The auger-hole method is applicable to an unconfined aquifer of homogeneous soil properties with shallow water table. This method provides an estimated horizontal value of $\mathrm{K}$ of the soil within the aquifer. But if the following four cases below does exist, it does not yield a reliable value of $\mathrm{K}$ : the cases are, if: the water table is above the soil surface, artesian conditions exist, layered soil structure exist, highly permeable small strata occurs [1]. However, the method is simple and has the advantage of using the soil water, and it is not affected so much by the presence of rocks or root holes adjacent to it [3]. Two formulae are used for the auger hole method; the [9], developed $\mathrm{K}$ for a homogeneous soil having no stratification and based on the assumption that: the water table is not lowered around the auger hole when water is pumped out of it, water flows horizontally into the sides of the auger hole and vertically up through the bottom of the hole (Figure 1).

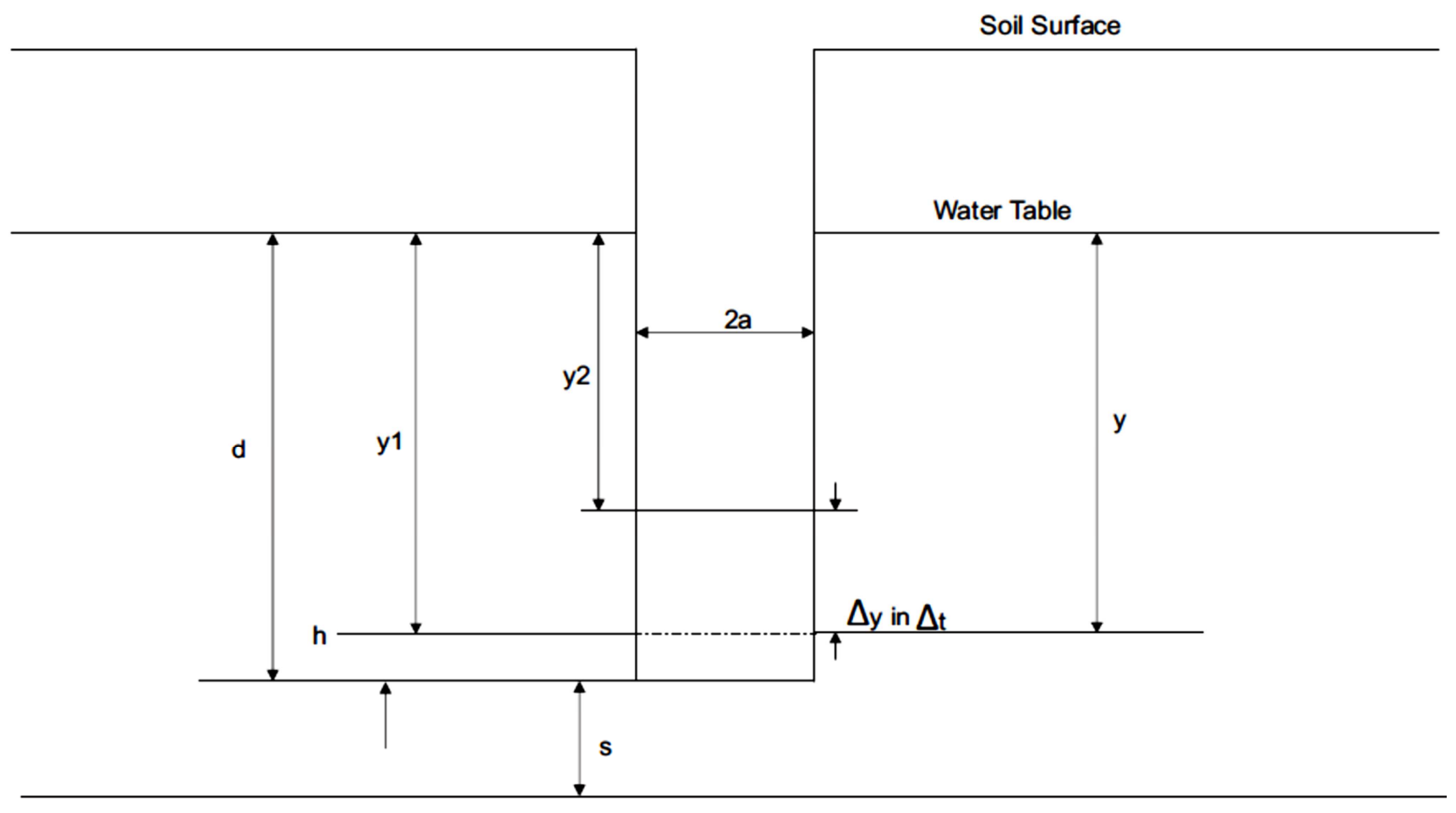

Source: [10]

Figure 1. Auger Hole. 
For a hole which does not reach an impermeable layer:

$$
\mathrm{K}=\frac{2.3 \mathrm{as}}{2 \mathrm{~d}+\mathrm{a}} \log _{1} / \mathrm{y}_{2}
$$

and for a hole which terminates at an impermeable layer:

$$
\mathrm{K}=\frac{2.3 \mathrm{as}}{2 \mathrm{dt}} \log _{1} / \mathrm{y}_{2}
$$

Where, $\mathrm{K}$ is the saturated hydraulic conductivity $\left(\mathrm{m} \mathrm{day}^{-1}\right)$, $\mathrm{a}$ is radius of auger hole $(\mathrm{m}), \mathrm{s}$ is a constant $=[\mathrm{ad} \sqrt{ }(0.19)]\left(\mathrm{m}^{-}\right.$ $\left.{ }^{1}\right), d$ is depth of a hole below a water table $(\mathrm{m}), \mathrm{t}$ is time for water table depth to change from $y_{1}$ to $y_{2}$ that is $\left(t=t_{2}-t_{1}\right)$, $\mathrm{y}_{1}$ is distance from water table to water level in the hole at time $t_{1}(m), y_{2}$ is distance from water table to water level in the hole at time $t_{2}(\mathrm{~m})$ [11], examines the auger hole problem and with the aid of numerical analysis, developed some empirical equations. The formula for homogeneous soil with an impermeable layer at a depth below the bottom of the auger hole (Figure 1) is given by:

$$
\mathrm{K}=4000 \mathrm{a} \Delta \mathrm{y} /\left[20+\left(\frac{\mathrm{d}}{\mathrm{a}}\right)\right]\left[2-\left(\frac{\mathrm{y}}{\mathrm{d}}\right)\right] \mathrm{y} \Delta \mathrm{t}
$$

where $\mathrm{K}, \mathrm{d}$ and a are as defined in equation (4) above, $\Delta \mathrm{y}$ is rise of water surface in an auger hole during the time interval $\Delta \mathrm{t}, \mathrm{y}$ is distance from static water table to elevation of water in the hole.

\subsection{The Well Pumping Tests}

\subsubsection{Equilibrium Condition for a Confined Aquifer}

Pumping test of a well is a field experiment in which the well is pumped at a controlled rate and water level drawdowns are measured in one or more observation wells sunk in the vicinity. The goal is to estimate hydraulic properties of the aquifer system [12]. Darcy's law of laminar flow through sand is combined with the equation of continuity to derive a well discharge equation which is used to estimate the value of $\mathrm{K}$ [13]. To derive the radial flow equation (which relates the well discharge to drawdown for a well completely penetrating a confined aquifer), (see Figure 2).

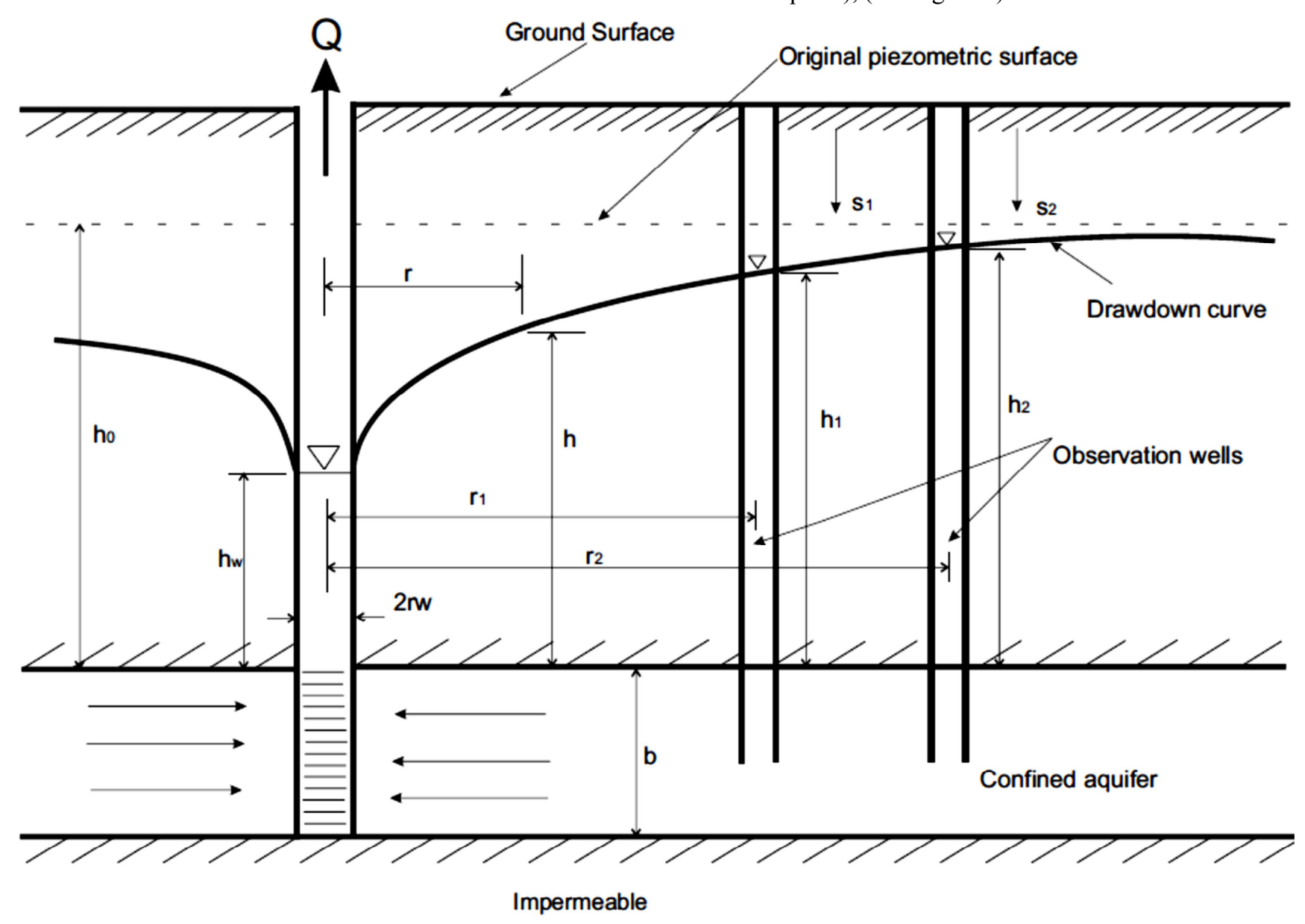

Source: [3].

Figure 2. Radial flow to well penetrating an extensive confined aquifer.

The well discharge, $\mathrm{Q}$ at any radial distance, $r$, is:

$$
Q=2 \pi K b r d h / d r
$$

Where: $\mathrm{Q}$ is the discharge $\left(\mathrm{m}^{3} /\right.$ day $), 2 \pi \mathrm{rb}$ is area of the well $\left(\mathrm{m}^{2}\right), \mathrm{b}$ is thickness of the aquifer $(\mathrm{m}) . \mathrm{K}$ is as defined in Equation (4) above, $\mathrm{i}=\mathrm{dh} / \mathrm{dr}$, is hydraulic gradient 
(dimensionless).

Furthermore, arranging equation (6) and integrating, yields:

$$
K=\frac{Q \ln \left(r_{2} / r_{1}\right)}{2 \pi b\left(h_{2}-h_{1}\right)}=\frac{Q \ln \left(r_{2} / r_{1}\right)}{2 \pi b\left(s_{1}-s_{2}\right)}
$$

From a practical standpoint, the drawdown, s rather than the head, $h$ is measured. Where: $r_{1}$ and $r_{2}$ are the distances of the observation wells from the pumped well $(\mathrm{m}), \mathrm{h}_{1}$ and $\mathrm{h}_{2}$ are heads of the respective observation wells $(\mathrm{m}), \mathrm{s}_{1}$ and $\mathrm{s}_{2}$ are the drawdowns in the observation wells 1 and 2 respectively.

For efficient derivation of $\mathrm{K}$ value, the aquifer is assumed homogeneous and isotropic, of uniform thickness and infinite areal extent; pumping must continue at uniform rate for a sufficient time to approach a steady state condition; the observation wells should be located close enough to the pumped well and finally, at the initial pumping, the piezometric surface is assumed horizontal [3].

\subsubsection{Equilibrium Condition for an Unconfined Aquifer}

Using Dupuit assumptions, an equation for steady, radial flow to a well in an unconfined aquifer (Figure 3 ) is derived. The well completely penetrates the aquifer to the horizontal base and a concentric boundary of constant head surrounds the well.

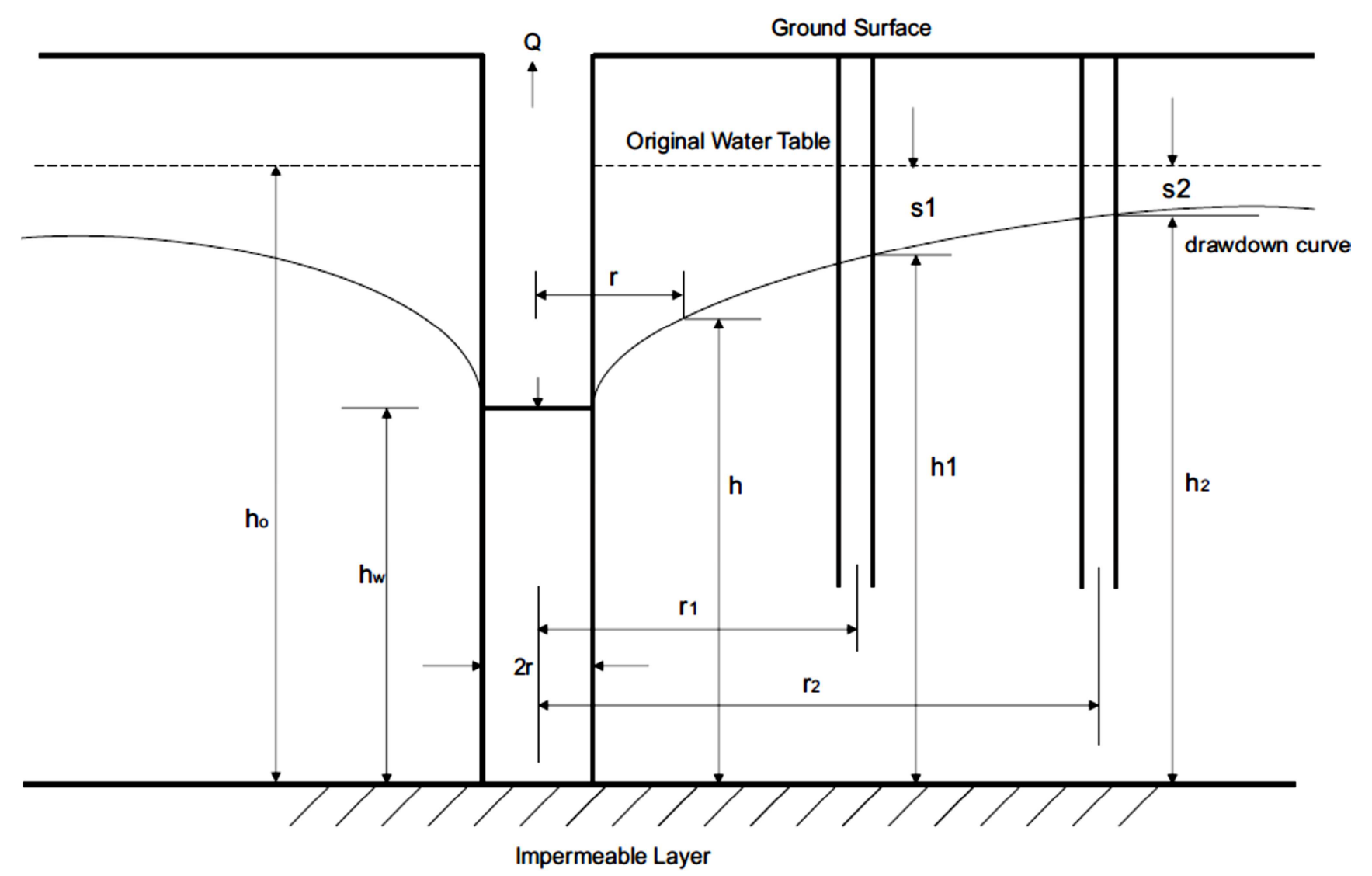

Source: [3].

Figure 3. Radial flow to well penetrating an unconfined aquifer.

The well discharge,

$$
Q=A V=A K i=2 \pi r K h d h / d r
$$

Where Q, A, r, K, i, are as defined in Equation (6). Rearranging equation (8) and integrating,

$$
K=\frac{Q \ln \left(r_{2} / r_{1}\right)}{\pi\left(h_{2}^{2}-h_{1}^{2}\right)}
$$

Where, $r_{1}$ and $r_{2} ; h_{1}, h_{2}$ are as defined in Equation (7).

\subsubsection{Non-Equilibrium Condition for a Confined Aquifer}

If a well penetrating a confined aquifer is pumped at the same rate, the influence of the discharge extends outward with time. The discharge equals the rate at which the head declines times the storage coefficient added to the area of influence. The head will continue to decline because the water comes from a reduction of storage in the aquifer, as long as the aquifer is effectively infinite, therefore, unsteady or transient flow exists (see Figure 2). As the area of influence expands, the rate of decline, however, continuously decreases.

The applicable differential equation in plane polar coordinates is:

$$
\left[\frac{\delta^{2} h}{\delta r^{2}}+\frac{1 \delta h}{r \delta r}\right]=\frac{S \delta h}{T \delta t}
$$


Where $\mathrm{h}$, is head, $\mathrm{r}$ is radial distance from the pumped well, $\mathrm{S}$ is storage coefficient, $\mathrm{T}$ is transmissivity; and $\mathrm{t}$ is the time since beginning of pumping.

Theis obtained a solution for Equation (10) based on the analogy between groundwater flow and heat conduction. By assumption that the well is replaced by a mathematical sink of constant strength and imposing the boundary conditions $h$ $=\mathrm{h}_{0}$ for $\mathrm{t}=0$, and $\mathrm{h} \rightarrow \mathrm{h}_{0}$ as $\mathrm{r} \rightarrow \infty$ for $\mathrm{t} \geq 0$, the solution

$$
S=\frac{Q}{4 \pi T} \int_{u}^{-u} e^{-} u \frac{d u}{u}
$$

Where,

$$
u=\frac{r^{2} s}{4 T t}
$$

$\mathrm{S}$ is the drawdown.

Equation (11) is known as the non-equilibrium, or Theis equation. The equation permits the determination of the constants $\mathrm{S}$ and $\mathrm{T}$ by means of pumping tests. The equation is widely applied in practice and is preferred over the equilibrium equation because a value for $\mathrm{S}$ can be obtained, only one observation well is required, a shorter period of pumping is required and no assumption of steady state flow condition is required.

However, for efficient determination of Equation (11) the following assumptions should be considered: the aquifer is homogeneous, isotropic of uniform thickness and of infinite areal extent; before pumping, the piezometric surface is horizontal; the well is pumped at a constant discharge rate; the pumped well penetrates the entire aquifer, and flow is everywhere horizontal within the aquifer to the well; the well diameter is infinitesimal so that storage within the well can be neglected; water removed from storage is discharged instantaneously with decline of head. Average values of $S$ and $\mathrm{T}$ can be obtained in the vicinity of a pumped well by measuring in one or more observation wells, the change in drawdown with time, under the influence of a constant pumping rate. Mathematical difficulties are encountered in applying Equation (11) and for that, several investigators have developed simpler approximate solutions that can be readily applied for field applications. Three methods, by Theis, Cooper- Jacob and Chow are described below with the necessary graphs.

In Theis method, Equation (11) may be simplified to:

$$
s=\frac{Q}{4 \pi T} W(u)
$$

Where $\mathrm{W}(\mathrm{u})$, termed the well function, is a convenient symbolic form of the exponential integral. Re-writing Equation (12):

$$
\frac{r^{2}}{t}=\frac{4 T u}{S}
$$

It can be seen that the relation between $\mathrm{W}(\mathrm{u})$ and $\mathrm{u}$ must be similar to that between $\mathrm{s}$ and $\left(\mathrm{r}^{2} / \mathrm{t}\right)$ because the terms in the parenthesis in the two equations are constants. Given this similarity, Theis suggested an approximate solution for $\mathrm{S}$ and $\mathrm{T}$ based on a graphic method or superposition. A plot on logarithmic paper of $\mathrm{W}(\mathrm{u})$ versus $\mathrm{u}$, known as a type curve, is prepared (see Figure 4).

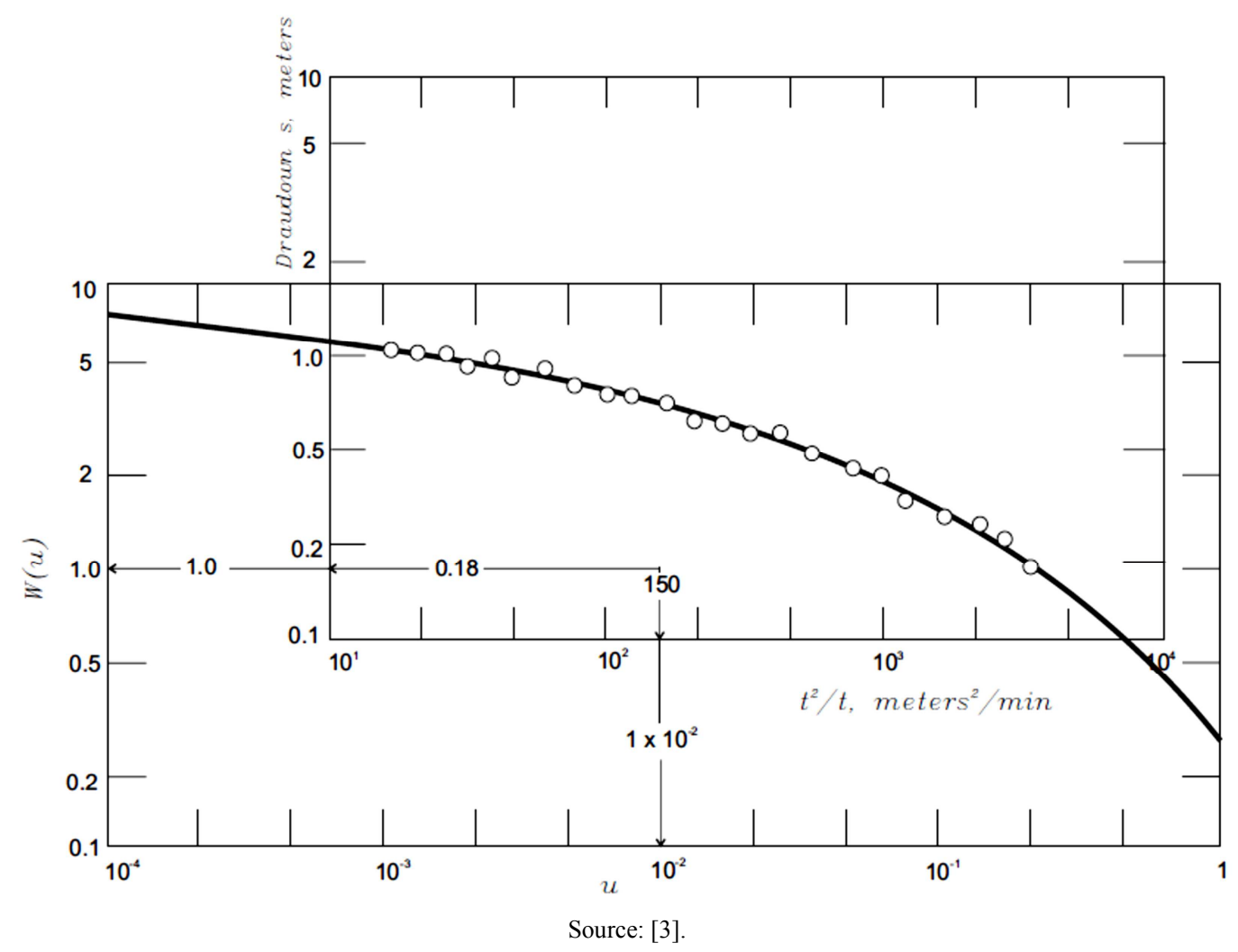

Figure 4. Theis method of superposition for solution of the non-equilibrium equation. 
Values of drawdowns are plotted against values of $\mathrm{r}^{2} / \mathrm{t}$ on logarithmic paper of the same size as for the type curve. The observed time-drawdown data are superimposed on the type curve, keeping the axes of the two curves parallel and adjusted until a position is found by trial where by most of the plotted points of the observed data fall on a segment of the type curve. Any convenient point is then selected, and the coordinates of these match points are recorded. With values of $\mathrm{W}(\mathrm{u}), \mathrm{u}, \mathrm{s}$ and $\mathrm{r}^{2} / \mathrm{t}$ thus determined, $\mathrm{S}$ and $\mathrm{T}$ can be obtained from Equations (13) and (14) respectively. Hence the value of $\mathrm{K}$ is obtained from:

$$
K=\frac{T}{b}
$$

Where $b$ is the thickness of the aquifer.

In Cooper-Jacob method, it is noted that for small values of $r$ and large values of $t, u$ is small. Re-writing and changing to decimal logarithms, this reduces to

$$
S=\frac{2.30 Q \log 2.25 T t}{4 \pi T r^{2} S}
$$

Therefore, a plot of drawdown, s versus the logarithm of $t$ forms a straight line (Figure 5).

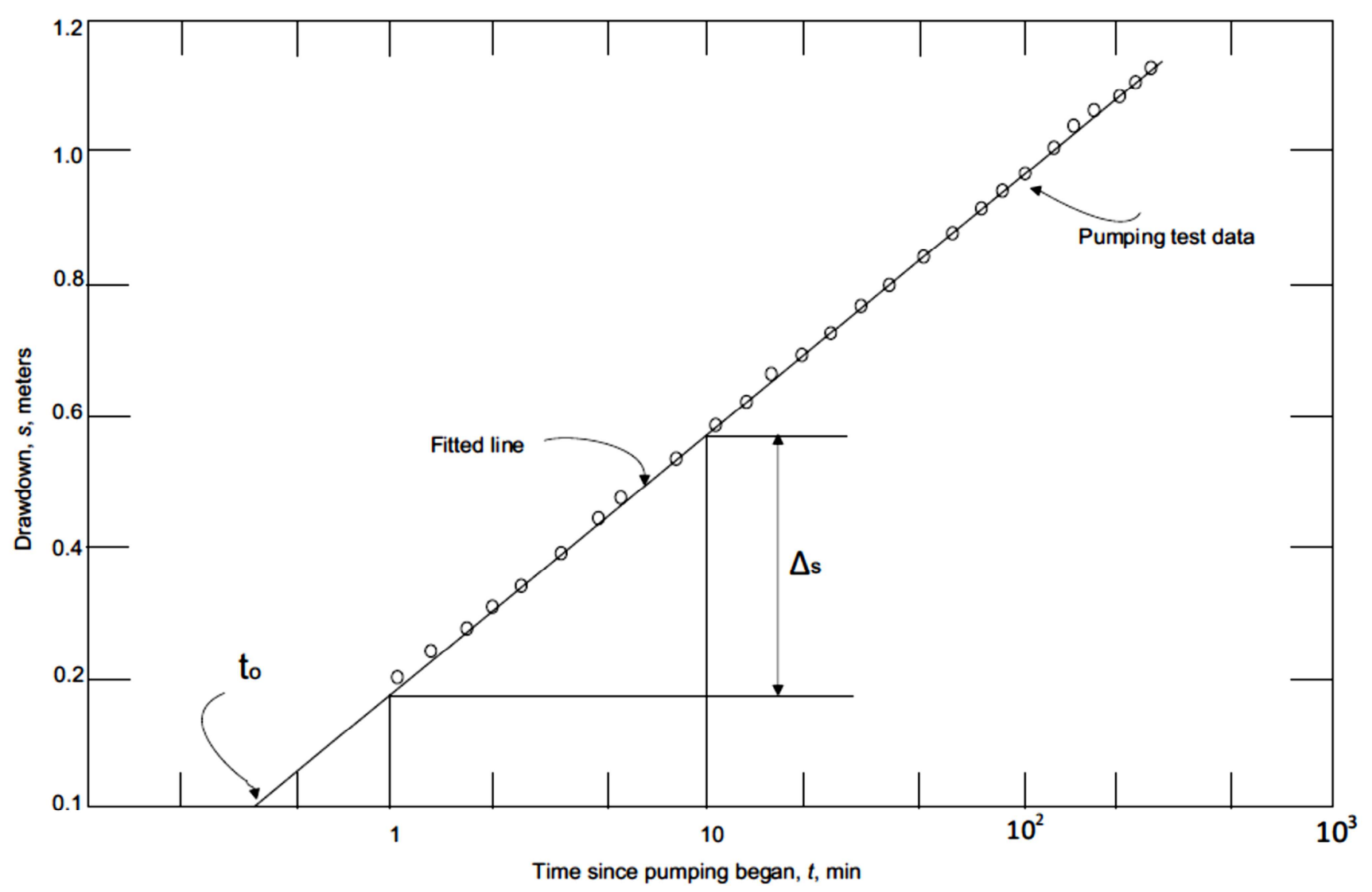

Source: [3].

Figure 5. Cooper-Jacob method for solution of the non-equilibrium equation.

Projecting this line to $\mathrm{s}=0$, where $\mathrm{t}=\mathrm{t}_{0}$

$$
S=2.25 T t_{0} / r^{2}
$$

A value of $\mathrm{T}$ can be obtained by noting that if $\mathrm{t} / \mathrm{t}_{0}=10$, then $\log \mathrm{t} / \mathrm{t}_{0}=1$; therefore, replacing s by $\Delta \mathrm{s}$, where $\Delta \mathrm{s}$ is the drawdown difference per $\log$ cycle of t, Equation (16) becomes

$$
T=\frac{2.30 Q}{4 \pi \Delta s}
$$

Hence, $\mathrm{K}$ is estimated using equation (15).

In Chow method of solution, he developed a method with the advantages of avoiding curve fitting and being unrestricted in its application. Also, measurements of drawdown in an observation well near a pumped well are made. The observed data are plotted on semi logarithmic paper in the same manner as for the Cooper-Jacob method. On the plotted curve (Figure 6), an arbitrary point is chosen and the coordinates $\mathrm{t}$ and $\mathrm{s}$ are noted, a tangent to curve is drawn at the chosen point and the drawdown difference $\Delta \mathrm{s}$ per log cycle of time is determined. F (u) is computed from

$$
F(u)=s / \Delta s
$$

And the corresponding values of $\mathrm{W}(\mathrm{u})$ and $\mathrm{u}$ were obtained from Figure (4). Finally, the formation constants $\mathrm{S}$ and $\mathrm{T}$ are computed using Equations (13) and (14) respectively. Hence $\mathrm{K}$ is computed using Equation (15). 


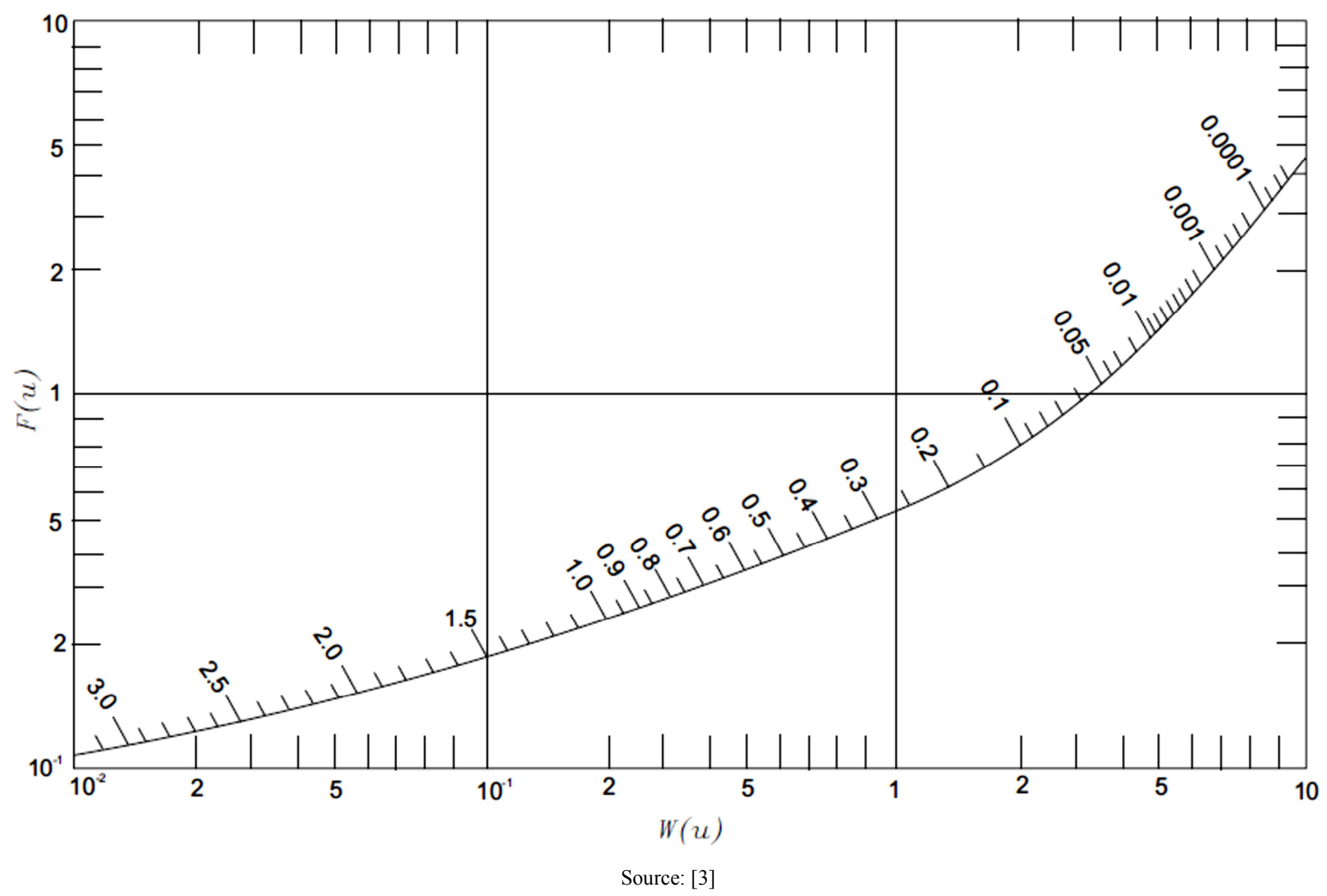

Figure 6. Relation among $F(u), W(u)$ and $u$.

\subsection{The Piezometer Method}

The piezometer method, like the auger-hole method, is applicable for determining the $\mathrm{K}$ of soils in an unconfined aquifer with a shallow water table. Unlike the auger-hole method, the piezometer method is appropriately designed for applications in layered soil aquifers and for determining either horizontal or vertical components of K. This method consists of installing a piezometer tube (Figure 7) into an auger hole drilled through the subsurface system without disturbing the soil. The piezometer tube should be long enough to partially penetrate the unconfined aquifer. The walls of the piezometer tube are totally closed except at its lower end, where the tube is screened to form a cylindrical cavity of radius (a) and height (L) within the aquifer [14]. Similar to the auger-hole method, the piezometer method is conducted by removing the water from the pipe and then measuring the rate of rise of the water within the pipe. $\mathrm{K}$ is then evaluated as a function of the geometrical dimension of the cavity in the piezometer tube, the dimensions of the aquifer, and the measured rate of rise of the water table in the tube. Depending on the relative height, L of the cavity as compared with its radius, a, the piezometer method can be used to determine the horizontal or vertical component of $\mathrm{K}$. Thus, if $\mathrm{L}$ is large compared to a, the results obtained reflect the horizontal component of $\mathrm{K}$. Otherwise, if $\mathrm{L}$ is small compared to a, then the vertical component of $\mathrm{K}$ is estimated. The piezometer method is especially suitable for determining $\mathrm{K}$ of individual layers in stratified subsurface systems [14]. [16] Developed a suitable equation for determining $\mathrm{K}$ in the form:

$$
K=\frac{\pi a^{2} \ln \frac{y_{1}}{y_{2}}}{S\left(t_{2}-t_{1}\right)}
$$

where $\mathrm{y}_{1}$ is the distance from a water table to water level in tube or piezometer at time, $\mathrm{t}_{1} ; \mathrm{y}_{2}$ is distance from a water table to water level in a tube at time, $\mathrm{t}_{2}$; a is radius of the tube; $t_{2}-t_{1}$ is time for water level to change from $y_{2}$ to $y_{1} ; S$ is obtained from an electric analogue and from field measurement [17]. 


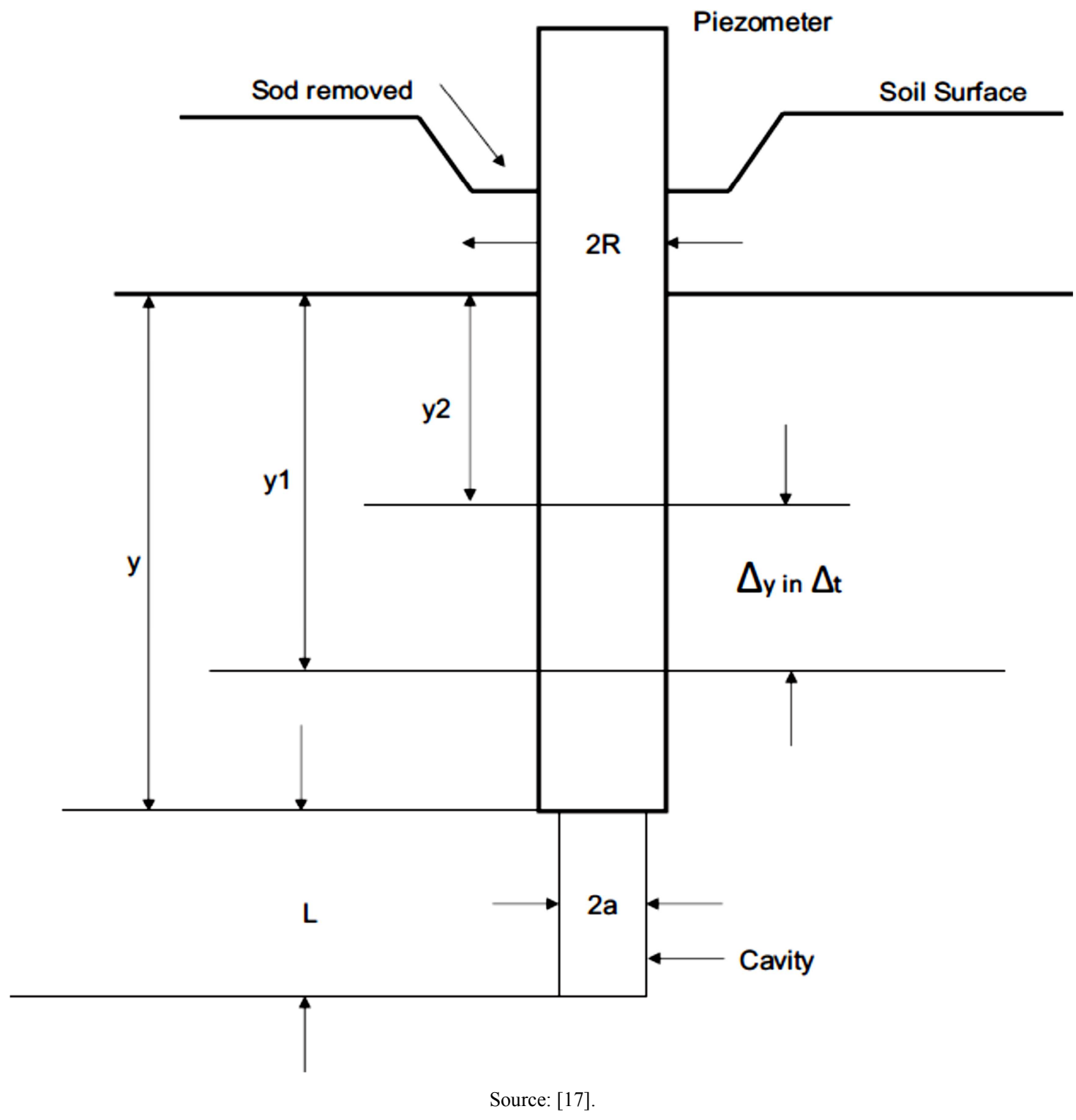

Figure 7. Piezometer method.

\subsection{The Two Well Method}

The two well method was carried out by [15] for nonlayered soils employing two auger holes rather than one (Figure 8). The two wells are of equal diameters and penetrate to the same depth below the water table preferably to an impermeable layer if one exists. Water is pumped at a steady rate out of one well and carried by a hose into the other, creating a small hydraulic head difference between the levels of water in the holes. An equation for determining $\mathrm{K}$ is:

$$
K=\frac{Q \cos h^{-1}\left(\frac{d}{2 a}\right)}{\pi L \Delta h}
$$

Where $\mathrm{Q}$ is pumping rate, $\mathrm{L}$ is the length of each well, $\mathrm{a}$, is radius of each hole, $\mathrm{d}$ is the distance between their vertical axis.

This equation is valid only if the holes penetrate to an impermeable layer else, an "end correction" must be applied to compensate for the flow entering the end of the auger hole. The end effect may be regarded as a flow, which in effect extends the length of the auger hole and, depends on the depth to impermeable layer as well as the dimensions of the hole. Childs suggest an addition of some $20 \mathrm{~cm}$ to the measured depth as an appropriate end correction for the holes of the radius used. The disadvantage is that, there is a tendency of surface sealing of the wells $[16,18]$. 


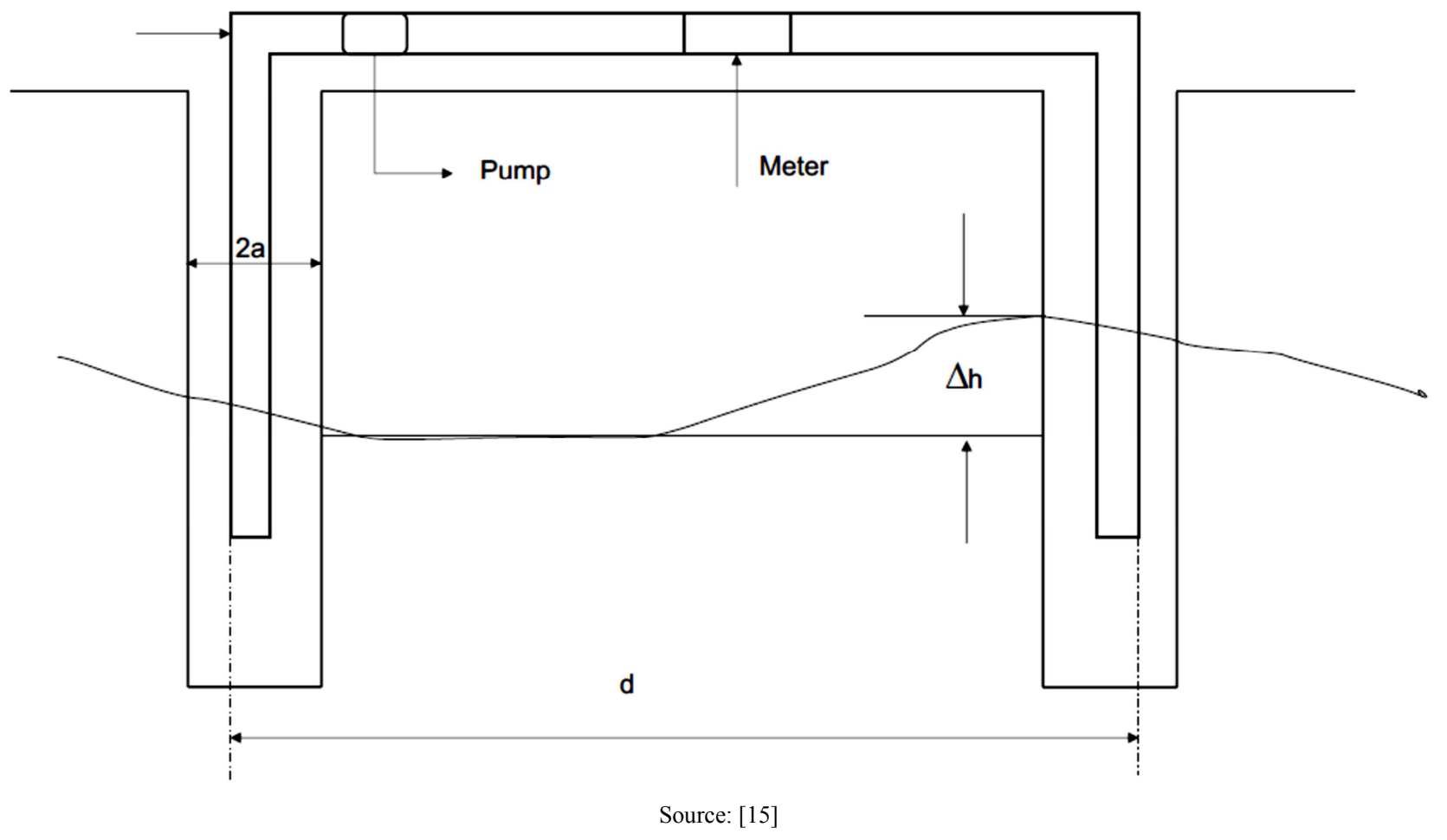

Figure 8. Two well method.

\subsection{The Tube Method}

Tube method is like the piezometer (Figure 7) method with a cavity of zero length [10]. The field equipment is made up of tubes of $0.2 \mathrm{~m}$ diameter, driven into the soil below a water table. An equipment is used for removing soil from the tube without puddling the soil surface. This method has these advantages: it can be used in-situations where there is a high water table; its vertical permeability can be measured, which is useful in drainage and recharge wells. The disadvantage is that, measurements are limited to a depth of approximately $0.9 \mathrm{~m}$ below the ground surface. $\mathrm{K}$ is then computed using Equation (20).

\subsection{The Four Well Method}

The four well method was designed to eliminate surface sealing that may occur in the two well method. Where sand liners are not used, soil pores on the wall of a well to which water is pumped may clog because the pumped water may contain sediment in suspension. [16] Suggested that two more cased wells of the piezometer type could be placed between the two wells as used by Childs. This arrangement should give a measure of the $\mathrm{K}$, which in theory will be independent of clogging effect of the walls of the wells. The rate of water movement between the two outer wells and difference in head would be measured. The ratio of the rate of water movement to the difference in head between the inner two wells would then be a measure of the K.

This is also applicable to the wells that reach an impermeable layer. Otherwise, "end correction" as earlier discussed under two wells method should be applied to compensate for the water entering the end of the auger holes.

\subsection{The Tracer Test}

Tracer test is carried out by measuring the time interval for a water tracer to travel between two observation wells or test holes [19]. Using a die such as sodium fluorescein, or a salt, such as calcium chloride, is convenient, inexpensive, easy to detect and safe [3]. By this method, the tracer is injected as a slug in one hole (A) after which samples of water are taken from another hole (B) to determine the time of passage of tracer. Because the tracer flow through the aquifer with the average interstitial velocity, $\mathrm{V}_{\mathrm{a}}$ then,

$$
V_{a}=K / \alpha\left(\frac{h}{L}\right)
$$

where $\mathrm{K}$ is as defined in Equation (3), $\alpha$ is porosity, $\mathrm{h}$ is the difference in head in the two wells, $\mathrm{L}$ is distance between the two wells measured from the well center. The interstitial velocity is also given by:

$$
V_{a}=L / t
$$

Where $t$ is the travel time of the tracer between the holes. Equating these two Equations (22) and (23) and solving for $\mathrm{K}$, yields:

$$
K=\alpha L^{2} / h t
$$

Although, this procedure is simple in principle, results are only approximations. The disadvantage of this method is that, if the holes are place far from each other and the travel time becomes long, the tracer may miss the downstream hole entirely $([3,20,21])$. 


\subsection{The Point Dilution}

The point dilution method is an alternative tracer technique. Here, a tracer is introduced into an observation well and thoroughly mixed with the contained water. Thereafter, as water flow into and from the well, repeated measurement of tracer concentration is made. Analysis of resulting dilution curve defines the groundwater velocity. This together with the measured water table gradient and Darcy's law, yield a localized estimate of the $\mathrm{K}$ and also the direction of ground water flow. That is:

$$
Q=A V=K i A=K A d h / d l
$$

Rearranging Equation (25):

$$
Q=K A\left(\frac{d h}{d l}\right)
$$

Hence:

$$
K=Q / A\left(\frac{d h}{d l}\right)
$$

Where $\mathrm{Q}, \mathrm{A}, \mathrm{V}$, and $\mathrm{i}(d h / d l)$ are as defined in Equation (6) ([3], [22]).

\subsection{The Cone Permeameter}

The cone permeameter is a device used for measuring insitu K. It is made up of two pressure transducers, which are mounted inside the cone permeameter probe with ports to the side. One transducer is mounted $15 \mathrm{~cm}$ and the other is $40 \mathrm{~cm}$ from the injection zone. A removable porous filter protects the sensors from damage during pushing. The filter and filter cavity are saturated with glycerine before the push for the fastest and most accurate pressure response during testing.

To measure the soil $\mathrm{K}$, the probe is pushed into the ground to the desired depth and a test is performed. The probe can then be pushed to the next depth for another test. The value of $\mathrm{K}$ is automatically indicated on the device meter. No soil or water is removed from the hole and the entire test can take less than 10 minutes at a given depth. The following are the benefits of the cone permeameter: Multiple testing depths during the same push, rapid measurement, no permanent well placement, minimizes effect of compacted soil due to tool emplacement, steady state test that yields real-time output of $\mathrm{K}$ value, save some time and money, the fastest method available for measuring $\mathrm{K}$. The disadvantage is that, it cannot measure $\mathrm{K}$ at great depth $([23,24])$.

\section{Summary}

Nine methods, thirteen types and fifteen different formulae for determining in-situ $\mathrm{K}$ were reviewed. Depending on the conditions of the soil, one or more formulae for determining $\mathrm{K}$ using each of the methods exists. From the review, there are three formulae for calculating $\mathrm{K}$ using auger hole, five formulae for pumping test of wells, and one each for the other remaining methods. Table 3.1 lists the summary highlights of the in-situ methods reviewed with their corresponding $\mathrm{K}$ formulae and the conditions for obtaining each formula with the advantages and disadvantages of each of the methods.

\section{Conclusion}

From the nine methods reviewed for determination of insitu $\mathrm{K}$, it is obvious that cone permeameter is the fastest and simplest ( $\mathrm{K}$ is automatically measured within 10 minutes as the device's probe is pushed into the desired depth in the ground), measuring $\mathrm{K}$ at different depths in a single push without the removal of soil or water from the hole. In terms of reliability, well pumping test of the non-equilibrium type is the most reliable and produces accurate results. Every other method is more or less related to each other and gives acceptable values of $\mathrm{K}$.

\section{Recommendations}

Other in-situ methods of determining hydraulic conductivity should be considered and reviewed. Conditions, advantages and disadvantages of the methods reviewed

\begin{tabular}{|c|c|c|c|}
\hline S/No. & In-situ methods & Types & Formulae \\
\hline 1 & Auger hole & $\begin{array}{l}\text { Hooghoudt's Method } \\
\text { Ernst Formula }\end{array}$ & $\begin{aligned} K & =\frac{2.3 a s}{2 d+a} \log y_{1} / y_{2} \\
K & =\frac{2.3 a s}{2 d t} \log y_{1} / y_{2} \\
K & =4000 a \Delta y /\left[20+\left(\frac{d}{a}\right)\right]\left[2-\left(\frac{y}{d}\right)\right] y \Delta t\end{aligned}$ \\
\hline 2 & Pumping test of wells & $\begin{array}{l}\text { Equilibrium condition for confined aquifer } \\
\text { Equilibrium condition for unconfined aquifer } \\
\text { Non-equilibrium condition for confined aquifer }\end{array}$ & $\begin{array}{l}K=\frac{Q \ln \left(r_{2} / r_{1}\right)}{2 \pi b\left(h_{2}-h_{1}\right)}=\frac{Q \ln \left(r_{2} / r_{1}\right)}{2 \pi b\left(s_{1}-s_{2}\right)} \\
\mathrm{K}=\frac{\mathrm{Q} \ln \left(\mathrm{r}_{2} / \mathrm{r}_{1}\right)}{\pi\left(\mathrm{h}_{2}^{2}-\mathrm{h}_{1}^{2}\right)} \\
\mathrm{K}=\frac{\mathrm{T}}{\mathrm{b}}, \text { Where, } \mathrm{T}=\frac{\mathrm{Q}}{4 \mathrm{~S} \pi} \mathrm{W}(\mathrm{u}) \text { and } \mathrm{S}=\left(\mathrm{t} / \mathrm{r}^{2}\right) 4 \mathrm{~T} \mathrm{u}, \mathrm{u}=\frac{\mathrm{r}^{2} \mathrm{~S}}{4 \mathrm{Tt}} \\
\mathrm{K}=\frac{\mathrm{T}}{\mathrm{b}} \text {, where } \mathrm{T}=2.30 \mathrm{Q} \\
4 \pi \Delta \mathrm{s} \text { and } \mathrm{S}=2.25 \mathrm{Tt}_{0} / \mathrm{r}^{2} \\
\mathrm{~K}=\frac{\mathrm{T}}{\mathrm{b}} \text {, where } \mathrm{T}=\frac{\mathrm{Q}}{4 \mathrm{~S} \pi} \mathrm{W}(\mathrm{u}) \text { and } \mathrm{S}=\left(\mathrm{t} / \mathrm{r}^{2}\right) 4 \mathrm{Tu}\end{array}$ \\
\hline 3 & Piezometers method & - & $\mathrm{K}=\frac{\pi \mathrm{a}^{2} \ln \frac{\mathrm{y}_{1}}{\mathrm{y}_{2}}}{\mathrm{~S}\left(\mathrm{t}_{2}-\mathrm{t}_{1}\right)}$ \\
\hline 4 & Two well method & - & $\mathrm{K}=\frac{\mathrm{Q} \cos \mathrm{h}^{-1}\left(\frac{\mathrm{d}}{2 \mathrm{a}}\right)}{\pi \mathrm{L} \Delta \mathrm{h}}$ \\
\hline
\end{tabular}
improved using practical experience.

Table 1. Hydraulic Conductivity (K) values of the in-situ Methods Reviewed. 


\begin{tabular}{llll}
\hline S/No. & In-situ methods & Types & Formulae \\
\hline 5 & Tube method & - & $\mathrm{K}=\frac{\pi \mathrm{a}^{2} \ln \frac{\mathrm{y}_{1}}{\mathrm{y}_{2}}}{\mathrm{~S}\left(\mathrm{t}_{2}-\mathrm{t}_{1}\right)}$ \\
6 & Four well method & - & $\mathrm{K}=\frac{\mathrm{Q} \cos \mathrm{h}^{-1}\left(\frac{\mathrm{d}}{2 \mathrm{a}}\right)}{\pi \mathrm{L} \Delta \mathrm{h}}$ \\
7 & Tracer test & - & $\mathrm{K}=\alpha \mathrm{L}^{2} / \mathrm{ht}$ \\
8 & Point dilution & - & $\mathrm{Q}=\mathrm{KA}\left(\frac{\mathrm{dh}}{\mathrm{dl}}\right)$ \\
9 & Cone permeameter & - & $\mathrm{K}$ is automatically indicated on the device's indicator. \\
\hline
\end{tabular}

Table 1. Continued.

\begin{tabular}{|c|c|c|c|}
\hline S/No. & Conditions & Advantages & Disadvantages \\
\hline 1 & Hole does not reach an impermeable layer & $\begin{array}{l}\text { Uses the soil water, not affected by the presence of } \\
\text { rocks or root holes adjacent to it. }\end{array}$ & $\begin{array}{l}\text { Water table should not be above soil } \\
\text { surface, there should be no artesian } \\
\text { condition, and there shouldn't be } \\
\text { layered and permeable soil structure. }\end{array}$ \\
\hline
\end{tabular}

Hole terminates at an impermeable layer: For homogeneous soil with an impermeable layer at great depth below the bottom of the auger hole

Aquifer is assumed homogeneous, isotropic \& uniform thickness, infinite areal extent; pumping must continue at uniform rate to approach a steady state condition; observation wells should be located close enough, piezometric surface is assumed horizontal.

The well completely penetrates the aquifer to the horizontal base and a concentric boundary of constant head surrounds the well.

2 Aquifer is assumed homogenous, isotropic of uniform thickness and of infinite areal extent. Piezometric surface is assumed horizontal, wel pumped at constant discharge rate, pumped well penetrates the entire aquifer, horizontal flow, well diameter infinitesimal.

When mall values of $r$ and large values of $t$ exist.

Plot on semi logarithmic paper in the same manner as for the Cooper-Jacob is carried out.

Unconfined aquifer with layered soil \& shallow water table.

Non-layered soils; holes penetrate below water

4 table to an impermeable layer; else, addition of $20 \mathrm{~cm}$ be applied to compensate for the flow entering end of auger hole.

$5 \quad$ High water table soil and measurements limited to a depth of $0.9 \mathrm{~m}$.

Same as in two well method

The tracer should be thoroughly mixed with the well water.

Filter cavity should be saturated with glycerine for fastest and accurate pressure response during testing.
Uses the soil water, not affected by the presence of layered and permeable soil structure.
Equation widely applied. Constants $\mathrm{S}$ and $\mathrm{T}$ are determined. Only one observation well is required. Shorter period of pumping. No assumption of steady state flow.

It avoids curve fittings and it is unrestricted in its application. Measurement of drawdowns in an observation well near a pumped well are made. Soil is not disturbed. Both horizontal and vertical component of $\mathrm{K}$ could be estimated.

There is no soil puddling of the exposed surface. It can be used in situations where there is a high water table. Its vertical permeability can be measured.

Clogging may occur due to presence of sediments in pumped water. End correction should be applied if well does not reach an impermeable layer.

Convenient, inexpensive, easy to detect and safe.

Convenient, inexpensive, easy to detect and safe.

Multiple testing depth in a single push, rapid measurement, no permanent well placement, minimizes effect of compacted soil, due to tool placement, steady state test that yields real-time output of $\mathrm{K}$ value, save time and money, fast,
It involves extra effort as logarithmic paper is used.

Mathematical difficulties are encountered in applying the equation for the non- equilibrium condition.

There is tendency of surface sealing of the wells.

Measurement are limited to depth of approximately $0.9 \mathrm{~m}$ below the ground surface.

If holes are place far from each other and the travel time becomes long, the tracer may miss the downstream hole completely.

It cannot measure $\mathrm{K}$ at great depth. 


\section{References}

[1] Hamill, L \& F. G. Bell (1986). Ground Water Resources Development, 1st Edition, Pp. 21-23.

[2] Waduwawatte, B., C. Bing and N. Kosuke (2004). Determination of Hydraulic Properties in Sloping Landscapes from Tension and Double-Ring Infiltrometers SSSA 3: 964970.

[3] Todd, D. K. (1980). Groundwater Hydrology, Second Edition, Willey, New York.

[4] Cameira, M. R., R. M. Fernando and L. S. Pereira (2003). Soil Macropore Dynamics Affected by Tillage and Irrigation for a Silt Loam Alluvial Soil in Southern Portugal. Soil Tillage Res. 70: 131-140.

[5] Kachanoski, R. G.; F. Zhang; G. W. Parkin \& D. E. Elrick (1999). Measurement of Hydraulic Properties during Constant Flux Infiltration. Soil Science Soc. Of America. http//soil.scijournals.org/cgi/content/full/63/4/793. Accessed December, 2007

[6] Vandervaere, J. P., M. Vauclin and D. E. Elrick (2000). Transient Flow from Tension Infiltrometers. I. The TwoParameter Equation. Soil Sci. Soc. Am. J. 64:1263-1272

[7] Van Beer, W. J. F. (1983). The Auger Hole Method. A Field Measurement of Hydraulic Conductivity of Soil below the Water Table, ILRI, Wageningen, Netherlands.

[8] Diserens, E. (1934) in Luthin, J. N. (1980). Drainage of Agricultural Lands. American Soc. Of Agronomy, Madison, Winsc.

[9] Hooghoudt, S. B. (1936). Bijdragen tot de Konnis Van Eenige Natuurkundige Grootheden Van Den Grond, 4. Versl. Landh; Ond. 42(13) B: Pp. 449-541. In: J. N. Luthin (ed.) Drainage of Agricultural Lands. American Soc. Of Agronomy, Madison, Winsc. Pp. 420-435.

[10] Luthin, J. N. (1980). Drainage of Agricultural Lands. American Soc. Of Agronomy, Madison, Winsc. Pp. 420-435.

[11] Ernst, L. F. (1950). Een Niewe Formulae Voor de Berekening Van De Door Laat Factor Met Boorgaten Methode. Rap. Land Bouwproefsta en Bodenkundig Inst. T. N. O; Groninggen. (Mimeo). In: J. N. Luthin (ed.) Drainage of Agricultural Lands. American Soc. Of Agronomy, Madison, Winsc. Pp. 420-435.

[12] Glenn, M. D. (2016). Pumping Tests. Aquifer Testing. HydroSOLVE, Inc.2303 Horseferry Court, Reston, Virginia, 20191, USA.

[13] Dupuits, J. (1863) in Luthin, J. N. (1980). Drainage of Agricultural Lands. American Soc. Of Agronomy, Madison, Winsc.

[14] Burk, L. \& P. G. Cook (2015). A Simple and Affordable System for Installing Shallow Drive Point Piezometer. Groundwater Monitoring and Remediation.

[15] Childs, E. C. (1953). The Measurement of Hydraulic Permeability of Saturated Soil In-Situ. Principles of a Proposed Method. Proc. Ray Soc. London. A 215: Pp.525535 .

[16] Kirkham, D. (1946). Proposed Method for Field Measurement of Permeability of Soil Below the Water Table. Soil Sci. Soc. Amer. Proc. 10 Pp. 58-68.

[17] Luthin, J. N. and Don, Kirkham (1949). A Pedometer Method for Measuring Permeability of Soil In-Situ below a Water Table. Soil Sci. Soc. of American Journal 68:349-358.

[18] Mendoza, G. and S. T. Steenhuis (2002). Determination of Hydraulic Behaviour of Hillsides with a Hill Slope Infiltrometer. Soil Sci. Soc. Am. J. 66:1501-1504.

[19] Jui-Sheng, C.; Chia-Shyun, C.; Hwa-Sheng, G. Chen-Wuing, L. (1999). A Two Well Method to Evaluate Transverse Dispersity for Tracer Tests in a Radially Convergent Flow Field. Journal of Hydrology, 1 Oct. 1999, Vol. 223(3):175197.

[20] Flint, L. E. and A. L. Flint (2002). The Soil Solution Phase. Porosity. P. 241-254. In J.H. Dane and G. C. Topp (ed.) Methods of Soil Analysis. Part 4. SSSA Book Ser. 5. SSSA, Madison, WI.

[21] Dyck, M. F., R. G. Kachanoski and E. de Jong (2003). LongTerm Movement of a Chloride Tracer under Transient, SemiArid Conditions. Soil Sci. Soc. Am. J. 67:471-477

[22] Reynolds, W. D., D. E. Elrick and E. G. Youngs (2002). The Soil Solution Phase. Single-Ring and Double or ConcentricRing Infiltrometers. Pp. 821-826. in J. H. Dane and G. C. Topp (ed.) Methods of Soil Analysis SSSA Book Ser. 5. SSSA, Madison, WI.

[23] Bill L., N. Mason, and V. Chipman (1999). Cone Permeameter In-Situ Permeability Measurements with Direct Push Techniques. Science and Engineering Associates, 3205 Richards Lane, Suite A, Santa Fe, NM 87505, WM'99 Conference, February 28 - March 4, 1999.

[24] Kejr, K. (2004). Cone Permeameter. http//www.geoprobe.com/products/tools/hydconductivity/conp ermde. Access October, 2007. 